\title{
Is propofol more neurotoxic in the developing brain?
}

\author{
Deshui Yu • Guangyun Sun
}

Received: 27 June 2014 / Accepted: 29 June 2014/Published online: 22 August 2014

(C) Japanese Society of Anesthesiologists 2014

\section{Keywords Anesthesia $\cdot$ Neurotoxicity $\cdot$ Neuroapoptosis}

To the Editor:

The recent study comparing the neurotoxic properties of propofol with thiopental in neonatal mice was of great interest [1]. However, we identified several issues that might flaw the conclusion.

First, the authors performed $\mathrm{SpO}_{2}$ and $\mathrm{CBF}$ monitoring instead of blood gas analysis to exclude the possibility that the neuroapoptosis is caused by hypoxia/hypercarbia. However, the synergistic action between intravenous anesthetics and sevoflurane might depress circulation and respiration, leading to hypoxia or hypercarbia that cannot be detected by $\mathrm{SpO}_{2}$ and $\mathrm{CBF}$ monitoring.

In addition, it is well known that developmental anesthetic neurotoxicity depends on the degree of anesthetic exposure, which includes both accumulative exposure time and the depth of anesthesia [2]. It is important to determine equipotent anesthetic doses before comparing the detrimental effects of potentially neurotoxic compounds [3]. In this study, the neuroapoptotic properties of the two intravenous anesthetics with different potencies were compared directly. Thiopental and propofol combined with sevoflurane might induce different depths of anesthesia. Therefore we want to raise a concern that the different neuroapoptosis should be attributed to the greater neurotoxic effect of propofol or incomparable doses of the two agents.

\section{References}

1. Tagawa T, Sakuraba S, Kimura K, Mizoguchi A. Sevoflurane in combination with propofol, not thiopental, induces a more robust neuroapoptosis than sevoflurane alone in the neonatal mouse brain. J Anesth. doi:10.1007//s00540-014-1822-x.

2. Deshui Y, Bin L. Developmental anesthetic neurotoxicity: from animals to humans? J Anesth. 2013;27:750-6.

3. Istaphanous GK, Howard J, Nan X, Hughes EA, McCann JC, McAuliffe JJ, Danzer SC, Loepke AW. Comparison of the neuroapoptotic properties of equipotent anesthetic concentrations of desflurane, isoflurane, or sevoflurane in neonatal mice. Anesthesiol. 2011;114:578-87.
D. Yu $\cdot$ G. Sun $(\bowtie)$

Department of Anesthesiology, The Second People's Hospital of Yibin, No. 96 North Street, Yibin 644000, Sichuan, People's

Republic of China

e-mail: ybanesthesia@sina.com 